Proceedings

\title{
Analysis of Genetic Diversity of Kazakh White-Headed Cattle Breed by Microsatellites Compare with Ancestral Breeds ${ }^{+}$
}

\author{
Alexandra S. Abdelmanova 1,*, Veronika R. Kharzinova ${ }^{1}$, Valeria V. Volkova 1, Arsen V. Dotsev ${ }^{1}$, \\ Alexander A. Sermyagin 1, Oxana I. Boronetskaya 1,2, Roman Yu Chinarov 1, Gottfried Brem 1,3 and \\ Natalia A. Zinovieva ${ }^{1}$
}

Citation: Abdelmanova, A.S.; Kharzinova, V.R.; Volkova, V.V.; Dotsev, A.V.; Sermyagin, A.A.; Boronetskaya, O.I.; Chinarov, R.Y.; Brem, G.; Zinovieva, N.A. Analysis of Genetic Diversity of Kazakh White-Headed Cattle Breed by Microsatellites Compare with Ancestral Breeds. Proceedings 2021, 68, x. https://doi.org/10.3390/xxxxx

Academic Editor:

Published: date

Publisher's Note: MDPI stays neutral with regard to jurisdictional claims in published maps and institutional affiliations.

Copyright: (c) 2021 by the authors. Submitted for possible open access publication under the terms and conditions of the Creative Commons Attribution (CC BY) license (http://creativecommons.org/licenses/by/4.0/).
1 L.K. Ernst Federal Research Center for Animal Husbandry, Dubrovitsy, Podolsk Municipal District, Moscow Region, 142132 Podolsk, Russia; preevetic@mail.ru; veronika0784@mail.ru; moonlit_elf@mail.ru; asnd@mail.ru; alex_sermyagin85@mail.ru; roman_chinarov@mail.ru; n_zinovieva@mail.ru

2 Timiryazev Russian State Agrarian University-Moscow Agrarian Academy, 49, ul. Timiryazevskaya, 127550 Moscow, Russia; liskun@rgau-msha.ru

3 Institut für Tierzucht und Genetik, University of Veterinary Medicine (VMU), Veterinärplatz, A-1210 Vienna, Austria; gottfried.brem@vetmeduni.ac.at

* Correspondence: preevetic@mail.ru; Tel.: +7-4967-65-11-63

† Presented at the 1st International Electronic Conference on Biological Diversity, Ecology and Evolution, 1531 March 2021; Available online: https://bdee2021.sciforum.net/.

\begin{abstract}
Kazakh White-headed is the local beef cattle breed, created in the beginning of 20 century by improving native Kazakh cattle by Hereford breed. The aim of our work was to trace the presence of ancestral genetic components in the modern population of this breed. The samples of modern representatives of Kazakh White-headed $(n=29)$ and Hereford $(n=25)$ breeds as well as historical specimens of native Kazakh breed $(n=2)$, dated by the first quarter of 20th century, were subjected to the study. We genotyped 11 microsatellite loci (BM1818, BM2113, BM1824, ETH10, ETH225, INRA023, SPS115, TGLA53, TGLA122, TGLA126, and TGLA227). For historical samples the PCR reaction were carried out in five replicates to determine the consensus genotypes for each locus. In total, we identified 82 microsatellite alleles. Five alleles, which were found in the historical specimens, were lost in the modern population. We observed the highest level of genetic diversity in historical samples. The modern population of Kazakh White-headed cattle was closer to Hereford breed as was revealed by calculation of pairwise Nei and FST genetic distances. The STRUCTURE clustering showed the visible presence the historical genetic components in the modern Kazakh White-headed cattle. The research results will be useful for developing the programs of conservation and sustainable use of Kazakh White-headed cattle.
\end{abstract}

Keywords: local cattle breed; historical DNA; microsatellites; genetic diversity

\section{Introduction}

Since ancient times, the Kazakh people led a nomadic life, driving cattle across the vast territory of Central Asia. At the beginning of the 20th century, their usual way of life was altered: the number of cities and number of citizens was increased; many grazing areas were plowed up for growing crops. The new conditions required a creating the breed that could not only withstand the harsh climate of Kazakhstan, but also to have an excelent growing capasity in the poor forage conditions of south steppe. Since 1930-th years native local Kazakh cows had been crossed with Herefords to developing a new beef breed that was named Kazakh White-headed breed [1]. 


\section{Experiments}

\subsection{Samples and Genotyping}

The samples of modern Kazakh White-headed (KZWH_M, $n=29)$ and Hereford (HRFD_M, $n=25$ ) breeds as well as historical specimens of native Kazakh breed (KZKH_H, $n=2$ ) were subjected to the study.

Sculls of native Kazakh breed, dated by the first quarter of the 20th century, were kept at the craniological collection of the Museum of Livestock named after E.F. Liskun (Moscow Agricultural Academy named after K.A. Timiryazev). The teeth were recovered from skulls, treated with hydrogen peroxide, and irradiated using ultraviolet light (254 $\mathrm{nm})$. Roots of teeth were milled by mixer mill into thin powder to extract DNA.

All works with historical specimens were performed in dedicated facility of the L.K. Ernst Research Centre for Animal Husbandry. DNA from modern samples was extracted using DNA Extran 2 kit (JSC Syntol, Russia) and from historical specimens-using COrDIS Extract Decalcine kit (GORDIZ LLC, Russia). We genotyped 11 microsatellite loci (BM1818, BM2113, BM1824, ETH10, ETH225, INRA023, SPS115, TGLA53, TGLA122, TGLA126, and TGLA227). For historical samples the PCR reactions were carried out in five replicates to determine the consensus genotypes for each locus.

\subsection{Statistical Data Analysis}

The calculating observed $(\mathrm{Ho})$ heterozygosity, unbiased expected heterozygosity $(\mathrm{UHE})$, unbiased inbreeding coefficient (UFIs), and rarefied number of alleles (AR) was performed by R package diveRsity [2]. GenAIEx 6.5 [3] was used to calculate the number and frequency of alleles. Pairwise Nei and Fst genetic distances, calculated by GenAIEx 6.5, were used to construct a phylogenetic network using the Neighbour-Net algorithm in SplitsTree 4.14.5 [4]. Principal component analysis (PCA) was performed using the R package adegenet [5] and visualised in the R package ggplot2 [6]. The data files were prepared in the software environment R3.5.0 [7]. The genetic structure was investigated using an admixture model with the option of correlated allele frequencies in the STRUCTURE 2.3.4 program [8]. We set a burn-in period to 10,000 iterations followed by 100,000 Markov chain Monte Carlo (MCMC) repetitions for each run.

\section{Results}

\subsection{Genetic diversity}

In total, we identified 82 microsatellite alleles in three cattle populations, including 73, 57 and 34 alleles in Kazakh White-headed, Hereford breeds and historical Kazakh cattle, respectively. All loci were polymorphic except for ETH225 in the historical population, which could be explained by the small sample size. The highest variability was observed for TGLA122 and TGLA227 (12 and 10 alleles, respectively), while ETH10 and BM1824 were the least polymorphic (4 alleles). Allelic variability in three breeds are summarized in Table 1.

Table 1. Allelic variability by loci in studied breeds.

\begin{tabular}{cccccc}
\hline \multirow{2}{*}{ Locus } & $\begin{array}{c}\text { Allele Ranges, } \\
\text { bp }^{\mathbf{a}}\end{array}$ & \multicolumn{5}{c}{ Number of Alleles Observed in Loci } \\
\cline { 3 - 6 } & $77-97$ & 4 & 9 & 7 & Total \\
\hline TGLA227 & KZ_H & KZWH_M & HRFD_M & 10 \\
BM2113 & $125-141$ & 3 & 7 & 7 & 9 \\
TGLA53 & $154-180$ & 4 & 9 & 5 & 9 \\
ETH10 & $215-221$ & 3 & 4 & 4 & 4 \\
SPS115 & $248-262$ & 2 & 6 & 5 & 6 \\
TGLA122 & $139-183$ & 4 & 10 & 8 & 12 \\
INRA23 & $198-214$ & 3 & 6 & 3 & 6 \\
TGLA126 & $113-123$ & 3 & 6 & 4 & 6 \\
BM1818 & $260-268$ & 3 & 6 & 5 &
\end{tabular}




\begin{tabular}{cccccc} 
ETH225 & $140-154$ & 1 & 6 & 6 & 7 \\
BM1824 & $178-188$ & 4 & 4 & 3 & 4 \\
Sum by all loci & 34 & 73 & 57 & 82 \\
\hline
\end{tabular}

a allele sizes were standardised according to International Society of Animal Genetics (ISAG) International Bovine (Bos Taurus) short tandem repeat (STR) typing comparison test 2018-2019).

Comparing the genotypes of Kazakh White-headed breed with their ancestral breeds showed that 4 and 5 alleles, distributed in the Hereford and native Kazakh breed, respectively, were lost in the Kazakh White-headed population. At the same time, 16 novel alleles that were not observed in ancestral breeds were found in Kazakh White-headed breed.

We observed the highest level of genetic diversity in the native Kazakh cattle breed, while the Hereford cattle were the least divergent. The significant deviation from the Hardy-Weinberg equilibrium in heterozygote number ( $\mathrm{uF}$ Is $=-0.100$, excess of heterozygotes) was observed only for historical population (Table 2).

Table 2. Summary statistics based on eleven STR markers.

\begin{tabular}{cccccc}
\hline Population & $\boldsymbol{n}$ & Ho $(\mathbf{M} \pm$ SE) & uHE $(\mathbf{M} \pm$ SE) & AR $(\mathbf{M} \pm$ SE) & uFIs (CI) \\
\hline KZKH_H & 2 & $0.864 \pm 0.097$ & $0.788 \pm 0.090$ & $3.091 \pm 0.285$ & $-0.100(-0.165 ;-0.035)$ \\
KZWH_M & 29 & $0.740 \pm 0.038$ & $0.731 \pm 0.029$ & $2.737 \pm 0.096$ & $-0.011(-0.062 ; 0.040)$ \\
HRFD_M & 25 & $0.662 \pm 0.062$ & $0.654 \pm 0.051$ & $2.505 \pm 0.143$ & $0.004(-0.068 ; 0.076)$ \\
\hline
\end{tabular}

$n$, number of individuals; $\mathrm{Ho}$, observed heterozygosity; $\mathrm{UHE}$, unbiased expected heterozygosity; $\mathrm{A}$, rarefied allele richness; uFIs, unbiased inbreeding coefficient; $\mathrm{M}$, mean value; $\mathrm{SE}$, standard error; $\mathrm{CI} 95 \%$, range variation coefficient of uFis at a confidence interval of $95 \%$.

\subsection{Genetic Structure and Relationship between Populations}

The first component (PC1) in the principal component analyses (PCA) (Figure 1), which was responsible for $6.111 \%$ of the genetic variability, showed the clear separation of historical specimences from the modern ones. Distant localization of historical specimens from each other at PCA plot can be due to the absence of the aimed breeding strategy and chaotic mating of animals in that time.

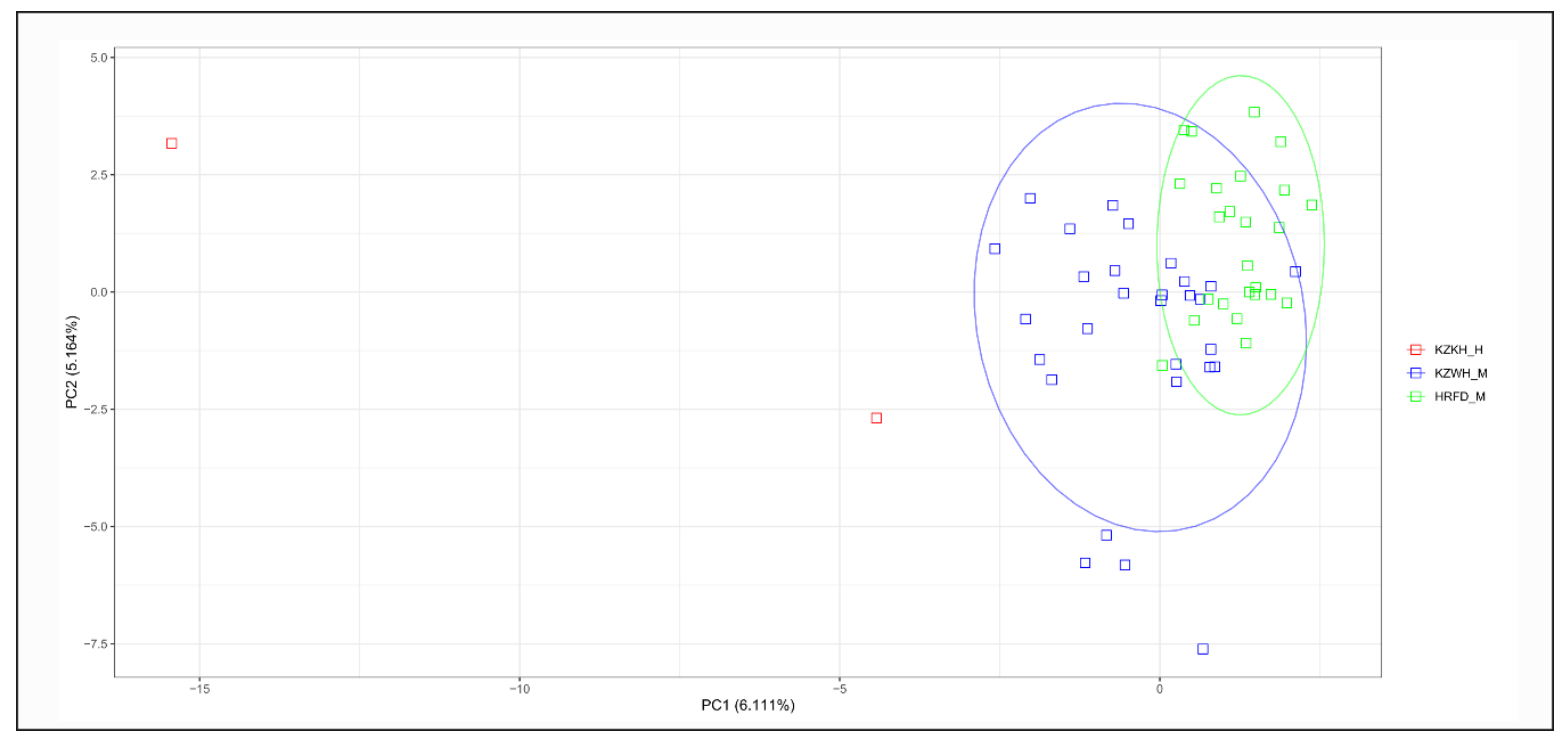

Figure 1. Principal component analysis (PCA) of historical and modern cattle populations. $X$-axis, principal component 1 (PC1); Y-axis, principal component 2 (PC2); KZKH_H_historical population of native Kazakh cattle; KZWH_M-modern population of Kazakh White-headed breed; HRFD_M-modern population of Hereford breed.

The calculation of the pairwise Nei $\left(\mathrm{D}_{\mathrm{N}}\right)$ and Fst genetic distances showed, as was expected, the most closeness of modern Kazakh White-headed cattle to Hereford breed $\left(\mathrm{D}_{\mathrm{N}}=0.157, \mathrm{Fst}=0.034\right)$. 
According to calculations of $\Delta \mathrm{K}$ values for the number of clusters $(\mathrm{k})$ from 1 to 6 , the most probable number of ancestral populations which were contributed to developing of studied breeds was 2. Analysis of genetic structure of studied breeds at $\mathrm{k}=2$ (Figure 2) showed the visible presence of the historical Kazakh-specific genetic components in the modern population of Kazakh White-headed breed.

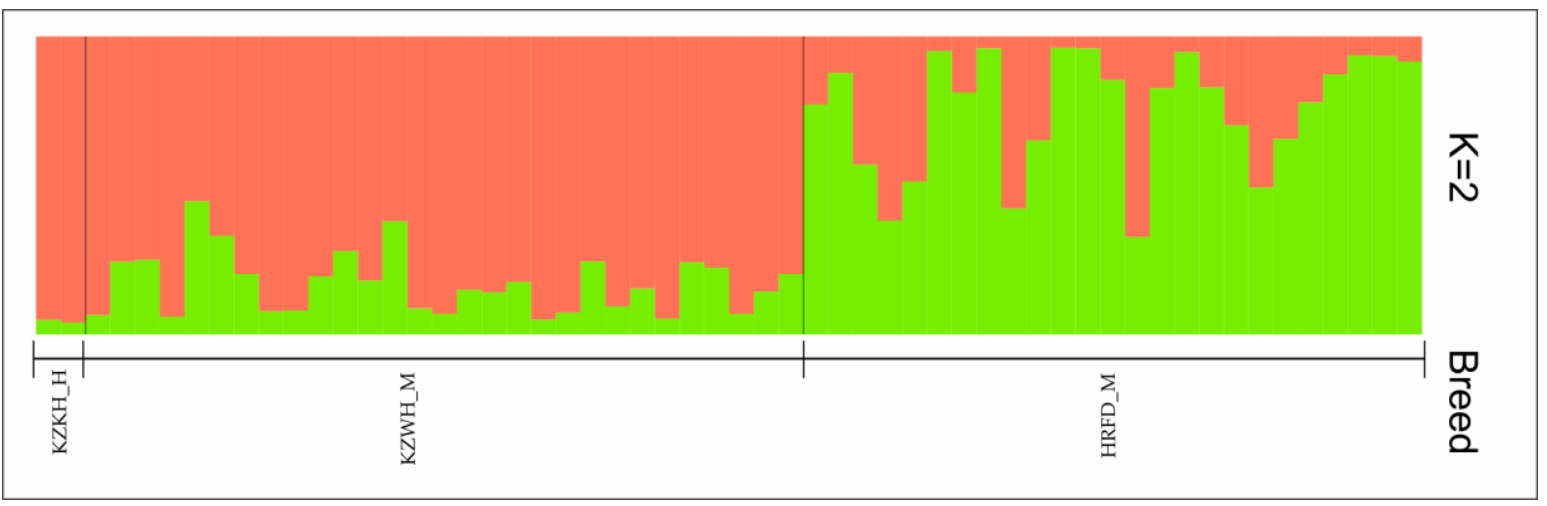

Figure 2. Genetic structure of historical and modern cattle populations. KZKH_H_historical population of native Kazakh cattle; KZWH_M-modern population of Kazakh White-headed breed; HRFD_M-modern population of Hereford breed.

\section{Discussion}

The study of museum and archeological samples can help to shed the light on the history of the livestock breeds [9-11]. In this study, we were able to obtain the valid genotypes for 11 microsatellites loci for the historical specimens of native Kazakh cattle dated by the first quarter of 20th century. We observed the higher level of genetic diversity in historical population compared to modern population of Kazakh cattle. The possible explanation can be, that only the part of Kazakh cattle were used for developing modern population of Kazakh White-headed breed. Higher selection pressure and use of the limited number of sires can be considered as additional factors leading to the the decrese of genetic diversity. Meanwhile, genetic diversity of the modern Kazakh White-headed breed was higher than one in the modern Hereford breed, that is in general agreement with other studies [12-14] showed the lower level of genetic diversity in transboundary commercial breeds comparing to local breeds.

\section{Conclusions}

Comparative molecular genetic studies of modern Kazakh White-headed cattle and museum specimences of their ancestor - native Kazakh cattle, dated by the first quarter of 20th century, revealed the maintainance of the historical genetic components in the modern population. Our results could be useful for developing the programs of conservation and sustainable use of Kazakh White-headed cattle.

Author Contributions: Conceptualization, N.A.Z. and G.B; methodology, A.S.A., V.R.K. and N.A.Z.; software, A.S.A. and A.V.D.; investigation, A.S.A., V.R.K., V.V.V., A.I.M., A.A.S. and R.Y.C.; provision of samples, O.I.B.; writing - original draft preparation, A.S.A. and N.A.Z.; writing - review and editing, A.V.D., A.A.S., G.B. and N.A.Z.; supervision, project administration, and funding acquisition, N.A.Z All authors have read and agreed to the published version of the manuscript.

Acknowledgments: The study was funded by the Ministry of Science and Higher Education of the Russian Federation theme 0445-2019-0024 (modern samples) and by the RSF No. 19-76-20012 (historical samples).

Conflicts of Interest: The authors declare no conflict of interest. The funders had no role in the design of the study: in the collection, analyses, or interpretation of data; writing of the manuscript; or decision to publish the results. 
1. Dmitriev, N.G.; Ernst, L.K. Animal Genetic Resources of the USSR; FAO and UNEP: Rome, Italy, 1989; Available online: http://www.fao.org/3/ah759e/AH759E07.htm (accessed on 10 February 2021).

2. Keenan, K.; McGinnity, P.; Cross, T.F.; Crozier, W.W.; Prodöhl, P.A. diveRsity: An R package for the estimation and exploration of population genetics parameters and their associated errors. Methods Ecol. Evol. 2013, 4, 782-788.

3. Peakall, R.; Smouse, P.E. GenAlEx 6.5: Genetic analysis in Excel. Population genetic software for teaching and research--an update. Bioinformatics 2012, 28, 2537-2539, doi:10.1093/bioinformatics/bts460.

4. Huson, D.H.; Bryant, D. Application of Phylogenetic Networks in Evolutionary Studies. Mol. Biol. Evol. 2005, 23, 254-267, doi:10.1093/molbev/msj030.

5. Jombart, T. adegenet: A R package for the multivariate analysis of genetic markers. Bioinformatics, 2008, 24, 1403-1405.

6. Wickham, H. Ggplot2: Elegant Graphics for Data Analysis (Use R!); Springer: New York, NY, USA, 2009; ISBN 978-0-387-98140-6.

7. R Core Team. R: A Language and Environment for Statistical Computing; R Foundation for Statistical Computing: Vienna, Austria, 2018; Available online: https://www.R-project.org (accessed on 10 February 2021).

8. Pritchard, J.K.; Stephens, M.; Donnelly, P. Inference of population structure using multilocus genotype data. Genetics 2000, 155, 945-959.

9. Edwards, C.J.; Connellan, J.; Wallace, P.F.; Park, S.D.E.; McCormick, F.M.; Olsaker, I.; Eythórsdóttir, E.; MacHugh, D.E.; Bailey, J.F.; Bradley, D.G. Feasibility and utility of microsatellite markers in archaeological cattle remains from a Viking Age settlement in Dublin. Anim. Genet. 2003, 34, 410-416, doi:10.1046/j.0268-9146.2003.01043.x.

10. Gargani, M.; Pariset, L.; Lenstra, J.A.; De Minicis, E.; European Cattle Genetic Diversity Consortium; Valentini, A. Microsatellite genotyping of medieval cattle from central Italy suggests an old origin of Chianina and Romagnola cattle. Front. Genet. 2015, 6, 68 .

11. Abdelmanova, A.S.; Kharzinova, V.R.; Volkova, V.V.; Mishina, A.I.; Dotsev, A.V.; Sermyagin, A.A.; Boronetskaya, O.I.; Petrikeeva, L.V.; Chinarov, R.Y.; Brem, G.; et al. Genetic Diversity of Historical and Modern Populations of Russian Cattle Breeds Revealed by Microsatellite Analysis. Genes 2020, 11, 940, doi:10.3390/genes11080940.

12. Berthouly-Salazar, C.; Thévenon, S.; Van, T.N.; Nguyen, B.T.; Pham, L.D.; Chi, C.V.; Maillard, J.-C. Uncontrolled admixture and loss of genetic diversity in a local Vietnamese pig breed. Ecol. Evol. 2012, 2, 962-975, doi:10.1002/ece3.229.

13. Zhang, G.X.; Wang, Z.G.; Chen, W.S.; Wu, C.X.; Han, X.; Chang, H.; Zan, L.S.; Li, R.L.; Wang, J.H.; Song, W.T.; et al. Genetic diversity and population structure of indigenous yellow cattle breeds of China using 30 microsatellite markers. Anim. Genet. 2007, 38, 550-559, doi:10.1111/j.1365-2052.2007.01644.x.

14. Ba, N.V.; Arakawa, A.; Ishihara, S.; Nam, L.Q.; Thuy, T.T.T.; Dinh, N.C.; Ninh, P.H.; Cuc, N.T.K.; Kikuchi, K.; Pham, L.D.; et al. Evaluation of genetic richness among Vietnamese native pig breeds using microsatellite markers. Anim. Sci. J. 2020, 91, e13343, doi:10.1111/asj.13343. 